\title{
Direitos humanos e polícia
}

\author{
Human rights and police
}

\author{
Rosimeri Aquino da Silva \\ Leônidas Roberto Taschetto*
}

\begin{abstract}
Resumo: Os problemas na segurança pública brasileira jamais estiveram tão evidentes como hoje. Noticiados, televisionados, espetacularizados, discutidos, investigados e criticados, estão na pauta das agendas de sociólogos, antropólogos, criminalistas, especialistas em segurança pública e nos demais setores da sociedade civil que, cada vez, explicitam o seu descontentamento com o trabalho das nossas polícias. O tema é espinhoso, polêmico, mas apaixonante. Incluímo-nos entre os tantos descontentes com nossas polícias contribuindo aqui para a qualificação destas discussões com alguns tópicos de nossa experiência como educadores em cursos de atualização e de formação de policiais. Inspiramo-nos nas idéias de Foucault em torno da problemática do poder e da violência e sobre a formação histórica das sociedades capitalistas para pensarmos os problemas na segurança pública. Propomos uma mudança no habitus das instituições policiais, "retirando-lhes" desses espaços estratificados e hierarquizados, entendendo, desse modo, a formação e a atualização como lugares privilegiados de mudanças.
\end{abstract}

Palavras-chave: Direitos humanos; Educação; Trabalho policial; Formação e atualização de policiais

\begin{abstract}
The problems in the Brazilian public safety were never as evident as today. Announced, televised, (made/turned into a show), discussed, investigated and criticized, they on the agenda of the sociologists, anthropologists, criminologists, specialists in public safety and other sections of the civil society that, every time, express their dissatisfaction with the work of our police. The theme is thorny, controversial, but captivating. We include ourselves among the so many ones unhappy with our police contributing here to the qualification of these discussions with some topics of our experience as educators in updating courses and of police formation. We were inspired by the ideas of Foucault around the problem of the power and of the violence and about the historical formation of the capitalist societies for us to think the problems about the public safety. We propose a change in the habitus of the police institutions, taking them away from their/removing them from their stratified and nested spaces, understanding, this way, the formation and the updating as privileged places of changes.
\end{abstract}

Key words: Human rights; Education; Police work; Formation and police updating

* Rosimeri Aquino da Silva é doutora em Educação pela Ufrgs, professora da Facos, Osório, Brasil.<rosimeri_silva@ig.com.br>. Leônidas Roberto Taschetto é doutor em Educação pela Ufrgs, Porto Alegre, Brasil.

\begin{tabular}{|l|l|l|l|l|l|}
\hline Civitas & Porto Alegre & v. 8 & n. 3 & p. 454-465 & set.-dez. 2008 \\
\hline
\end{tabular}




\section{Contextualização da experiência}

Além do texto da Declaração Universal dos Direitos Humanos, é possível encontrar um conjunto de leis brasileiras ${ }^{1}$ que trata da política antidiscriminatória, documentação civil, dos crimes de tortura e do programa nacional de direitos humanos. Os conteúdos destes documentos foram utilizados por professores da disciplina de Direitos Humanos, em cursos destinados à formação e à atualização de policiais, civis e militares, e de agentes penitenciários empossados durante a gestão de 1999-2002, assim como a outros servidores que já atuavam na segurança pública do Rio Grande do Sul.

A tentativa neste artigo será a de tecer conexões entre a definição de poder de Michel Foucault e o fenômeno da violência no cenário brasileiro. Procuramos investigar em que medida a definição foucaultiana de poder contribui para o entendimento dos múltiplos aspectos da violência contemporânea, considerando esta abordagem a partir de nossa experiência pedagógica na formação e atualização de policiais. Tal experiência se propunha a redimensionar o trabalho policial à luz dos tratados internacionais sobre $o$ uso da força e da arma de fogo, considerando-se o déficit no que se refere à normatização e padronização dos procedimentos policiais no Brasil, o que ocasiona, não raras vezes, distorções no emprego da força e da arma de fogo, revelando abusos de poder nas abordagens dos policiais da linha de frente. As conseqüências dessas distorções e abusos acabam se traduzindo em alvos de críticas e denúncias de organismos nacionais e internacionais de proteção dos direitos humanos, assim como por parte da população que exige mudanças no trabalho das polícias.

Foi nessa direção de ressignificação do trabalho policial que o Rio Grande do Sul estabeleceu uma parceria com a Universidade Federal do Rio Grande do Sul, por intermédio de sua fundação (Faurgs), no sentido de constituir um corpo docente de pesquisadores que se responsabilizaria pelo projeto pedagógico em dois diferentes cursos: Curso de ações básicas de segurança pública: uso da força e da arma de fogo e Curso de formação integrada em segurança pública.

1 Brasil, Leis etc. Documentação Civil. Política Antidiscriminatória. Crimes de Tortura. Declaração Universal dos Direitos Humanos. Programa Nacional de Direitos Humanos. Brasília: Ministério da Justiça, Secretaria Nacional dos Direitos Humanos, 1998. Conteúdo: Lei no 9.454, de 7 de abril de 1997; Lei no 9.465, de 7 de julho de 1997; Lei no 9534, de 10 de dezembro de 1997; Lei no 7.716, de 5 de janeiro de 1989; Lei no 7.853, de 24 de outubro de 1989; Lei no 9.029, de 13 de abril de 1995; Decreto no 914, de 6 de setembro de 1993; Lei no 9.455, de 7 de abril de 1997. 


\section{Poder e violência}

O desaparecimento dos suplícios dos corpos foi o início de uma nova época preocupada em investir na "economia do castigo", tornando-se as punições cada vez menos diretamente físicas. Ao final do século $18 \mathrm{e}$ início do século 19, o lendário carrasco dá lugar à figura do carcereiro: "a melancólica festa de punição vai-se extinguindo" (Foucault, 1988b, p. 14). A arte de fazer o desviante sofrer fisicamente vai abrindo espaço a outra espécie de sofrimento, muito mais sutil e disciplinadora: "Em algumas dezenas de anos, desapareceu o corpo supliciado, esquartejado, amputado, marcado simbolicamente no rosto ou no ombro, exposto vivo ou morto, dado como espetáculo. Desapareceu o corpo como alvo principal da repressão penal" (ibid.).

As práticas punitivas corpóreas, os prolongados e meticulosos procedimentos de tortura física em que o carrasco poderia perfeitamente ser confundido com o criminoso foram progressivamente substituídos por um castigo cada vez menos corpóreo, um castigo incorporal que não excluía totalmente o corpo do sofrimento, mas estabelecia uma nova lógica na relação de contato físico entre carrasco e criminoso e no teatro mórbido de que se fazia acompanhar a pena imposta: "Não tocar mais no corpo, ou o mínimo possível, e para atingir nele algo que não é o corpo propriamente" (Foucault, 1988b, p. 16).

Esse período inaugura uma mudança em que a alma, mais do que o corpo, deve ser penalizada. Mas a arte de matar, contudo, não deixa de existir, ela continua ainda por longo período de tempo, sendo substituída por procedimentos mais rápidos e menos dolorosos, cada vez menos disposta como espetáculo público. A perda de um bem ou de um direito passa a ser incorporada de forma definitiva no sistema penal ocidental. Passa-se a investir na disciplina rígida do corpo, com interferência direta e subjetiva no direito à liberdade e restrição dela. Cabe lembrar que a privação da liberdade, na Idade Média, não era considerada uma sanção penal. O encarceramento simplesmente cumpria uma função temporária de guarda e contenção do réu até o momento do julgamento. Nesse sentido, a prisão existia somente como uma espécie de ante-sala de suplícios, servindo temporariamente de depósito-contenção e custódia do réu, em condições subumanas, onde o réu esperava a celebração de sua execução.

$\mathrm{Na}$ formação histórica das sociedades capitalistas, nas pesquisas que realizou sobre o nascimento da instituição carcerária e na constituição do dispositivo da sexualidade, Foucault localiza formas de poder sedutoras e 
táticas que têm uma eficácia produtiva, uma riqueza estratégica, uma positividade. Um tipo de poder que teria como objetivo atingir o corpo humano, não para destruí-lo, supliciá-lo, mutilá-lo, mas para aprimorá-lo, adestrá-lo, torná-lo útil e dócil para esta nova configuração social:

O que faz com que o poder se mantenha e que seja aceito é simplesmente que ele não pesa só como uma força que diz não, mas que de fato ele permeia, produz coisas, induz ao prazer, forma saber, produz discurso. Deve-se considerá-lo como uma rede produtiva que atravessa todo o corpo social muito mais do que uma instância negativa que tem por função reprimir (Foucault, 1988a, p. 8).

Ora, se pensarmos em diferentes momentos da história brasileira, estes pressupostos, à primeira vista, parecem inadequados para entendermos as relações de poder entre a sociedade e as instituições de segurança pública. As instituições policiais brasileiras foram constituídas e representadas, ao longo do tempo, como organizações sociais dotadas de poderes essencialmente repressivos, punitivos, baseados no recurso à força, à violência física, no exercício (i)legítimo da violência, da arbitrariedade e da tortura, conforme o pensamento weberiano.

Lembremos, por exemplo, os direitos individuais violados durante o período ditatorial do país, tempo no qual estavam interditadas as discussões relacionadas aos Direitos Humanos no seio das instituições de segurança pública. Tais lembranças parecem corroborar esse sentimento, quase generalizado nos dias atuais, de descrédito à eficácia e ao debate deste tema, pois...

As forças de segurança sob a ditadura de Médici contavam com o medo para ajudá-las a descobrir e eliminar os "inimigos internos" do Brasil. A repressão atingiu especialmente os grupos que tentavam organizar as classes trabalhadoras. Os sindicatos, por exemplo, eram submetidos a controles draconianos. Os membros do clero que tentassem organizar qualquer atividade potencialmente política passavam a ser vigiados, incomodados, quando não submetidos a humilhações mais graves. As forças de segurança também vigiavam de perto qualquer forma de organização envolvendo os moradores de favelas e os trabalhadores rurais (Skidmore, 1988, p. 354).

É bem provável que o medo e a intolerância dos militares com os guerrilheiros amparavam-se na crença de que a propaganda por eles empreendida poderia insurgir as massas trabalhadoras contra os dirigentes militares. 
Até 1973 os poucos remanescentes das guerrilhas haviam renunciado a essa crença. O governo Médici também disseminara o medo entre os membros da elite. As famílias de presos políticos raramente encontravam um advogado que quisesse patrocinar sua causa. A imprensa era outra instituição intimidada pela repressão. A prisão e a tortura de jornalistas, as pressões ou incentivos sobre os proprietários de jornais, juntamente com a censura direta, haviam reduzido quase toda a mídia, exceto uns poucos semanários de pequena circulação, à condição de líderes de torcida do governo, ou no mínimo de simples caixas de ressonância das informações geradas no palácio presidencial (Skidmore, 1988, p. 354).

Outro importante elemento a ser considerado é que a violência, diferente do que se poderia pensar, não é um fenômeno incompatível com a racionalidade, uma vez que a violência não irrompe do nada, como bem disse Foucault: "O que existe de mais perigoso na violência é sua racionalidade. Certamente a violência em si é terrível. Mas a violência encontra seu fundamento mais profundo na forma de racionalidade de que nos utilizamos" (Foucault, 1994, p. 38-39). Nesse sentido, a violência empreendida pelas polícias nos governos militares da América Latina, nas décadas de 1960 e 1970, era racionalmente fundamentada no combate ao vírus do comunismo que estaria assolando o território americano e que os militares piamente acreditavam tratar-se de uma ameaça à soberania nacional. Daí, então, a justificativa do emprego de métodos violentos contra todos aqueles que estariam pondo em risco a soberania nacional.

O emprego de métodos desumanos contra os inimigos não é uma exclusividade dos governos militares ditatoriais. Temos exemplos bem mais recentes e vivos, como a polêmica Prisão de Guantánamo, criada pelos Estados Unidos para isolar e interrogar prisioneiros considerados terroristas. É um tanto paradoxal a criação de uma prisão diferenciada na mais potente democracia ocidental: ao mesmo tempo em que se prega o direito a liberdade, presenciamos uma situação de exceção institucional, ou melhor, um Estado de exceção no qual os direitos humanos internacionais não têm o mesmo estatuto, a mesma legitimidade, pois não se sabe exatamente o que acontece com os presos naquela prisão, a que regime estão submetidos, se métodos de tortura e humilhação são utilizados.

O poder de punir nas sociedades contemporâneas prescinde das formas violentas de punição, da violência física que, como sabemos, é uma ação prática empregada, legitimamente, pelas instituições policiais. O poder de punir justificar-se-ia por meio de outros poderes, dentre eles o dos especialistas. O poder é exercido com o apoio de saberes especializados: conhecimentos e procedimentos técnicos e científicos, conhecimentos da 
psiquiatria, da antropologia criminal, da criminologia, conformando o que Foucault (1988b) denomina de estabelecimento do "complexo científicojudiciário". Entretanto, dispondo-nos, mesmo que provisoriamente, em dar importância a alguns dados, números e fatos relatados sobre o ofício policial, esse conceito de poder parece não ser o mais adequado para entendêlo. De modo amplo, a sociedade brasileira, no que diz respeito às práticas policiais de abordagem, do uso da força, da arma de fogo e até mesmo da investigação, estaria mais voltado ao exercício do poder soberano do que às modernas tecnologias apontadas por Foucault em Vigiar e punir. Algumas pesquisas sociológicas ${ }^{2}$ sobre a violência policial no cenário brasileiro apontam que o poder policial manifesta-se no seu excesso, enquanto violência, correspondendo aquilo que Foucault denomina de "formas patológicas ou enfermidades do poder".

Mas a afirmação de que nossas polícias teriam regredido ao estado de barbárie é assumir uma postura saudosista, é acreditar que tivemos outrora um modelo melhor, aliás, situação esta muito preconizada pela chamada banda podre da polícia. $\mathrm{O}$ que acontece é que, cada vez mais, essas instituições começam a abrir suas caixas-pretas às quais poucos tinham acesso, ou por pressão dos movimentos sociais ressurgidos após o fim da ditadura militar, ou por força do controle externo instituído pela Constituição de 1988, passando a estarem mais sujeitas a uma maior visibilidade. Não discordamos de que houve um considerável abrandamento das punições policiais. Por outro lado, não podemos deixar de reconhecer que ainda persiste o uso da violência física por parte dos órgãos de segurança pública, com modernas tecnologias de vigilância e punição. De modo imbricado, faz-se uso de procedimentos arcaicos e procedimentos ultramodernos. Ou seja, os procedimentos técnicos e as investigações sofisticadas, não raras vezes, podem acompanhar a tortura, o suplício, a violação dos direitos fundamentais.

Um conjunto de artigos reunidos na revista Tempo Social (v. 9, n. 1, maio 1997) nos fornece um panorama sobre o tema, sendo os títulos de alguns desses textos bastante sugestivos: Observações sobre a falência dos modelos policiais; Violência, crime e sistemas policiais; Crimes, vítimas e policiais, O medo da polícia e as graves violações dos direitos humanos... Mas a que tipo de poder se está aludindo nesses textos, uma vez que é o próprio Foucault quem diz que a violência não se confunde com o poder:

\footnotetext{
2 Ver, por exemplo, a revista Tempo Social (1989); Tavares dos Santos (1999); Publicações da Comissão de Direitos Humanos da Assembléia Legislativa do RS - Relatório Azul (1999-2000/ 2000-2001).
} 
Significa esto que debemos buscar el carácter propio de las relaciones de poder en la violencia que debio ser su forma primitiva, su secreto e permanente y su recurso último, lo que en última instancia aparece como su verdad cuando se le obliga a quitarse la máscara y a mostrarse tal como es. En efecto, lo que define una relación de poder es que es un modo de acción que no actúa de manera directa e inmediata sobre los otros, sino que actúa sobre sus acciones: una acción sobre la acción, sobre acciones eventuales o actuales, presentes o futuras. Una relación de violencia actúa sobre un cuerpo e sobre cosas: fuerza, somete, quiebra, destruye: cierra la puerta a toda posibilidad. Su polo opuesto sólo puede ser la pasividad, y si tropieza con cualquier otra resistencia no tiene más opción que intentar minimizarla. En cambio, una relación de poder se articula sobre los elementos, ambos indispensables para ser justamente una relacion de poder: que "el otro" (aquel sobre el cual ésta se ejerce) sea totalmente reconocido y que se mantega hasta el final como un sujeto de accion y que se abra, frente a la relación de poder, todo un campo de respuestas, reacciones, efectos y posibles invenciones (Foucault, 1988c, p. 14).

As práticas policiais punitivas, na realidade brasileira, se dariam na base da "porrada", exemplarmente e com eficácia, como bem ilustrou um policial a um morador de uma favela do Rio de Janeiro, no documentário do cineasta carioca João Moreira Salles intitulado "Notícias de uma Guerra Particular", onde aborda o narcotráfico na favela Dona Marta, do Rio de Janeiro (realizado em 1997 e veiculado a partir de 1998 na GNT): "Olha, meu amigo", disse o policial, "eu não quero saber se é velho, criança, aleijado, eu meto o cacete mesmo, e não quero que ninguém fale nada". Além disso, na introdução da coletânea da revista Tempo Social, os autores afirmam que algumas pesquisas sobre as imagens e representações que cidadãos comuns vêm constituindo sobre as forças policiais indicam que os policiais são percebidos, não raras vezes, como pessoas que aplicam a lei, de modo insatisfatório, denunciando um descrédito acentuado nas instituições policiais, no que diz respeito a sua capacidade de resolução dos conflitos sociais.

Estudos sobre a violência, de autoria de Sérgio Adorno e Nancy Cardy (1999), apontam que inúmeras denúncias de abusos cometidos contra populações desprovidas de proteção legal multiplicaram-se no curso do processo de transição democrática. Isso representou um paradoxo para algumas pessoas que acreditavam que a volta ao Estado democrático e de direito interromperia o processo de violação dos direitos. Talvez isso acontecesse porque havia um debate - especialmente nos segmentos 
sociais organizados e clandestinos que se contrapunham aos regimes militares - acerca das atrocidades cometidas contra presos políticos. Contudo, não podemos dizer que as violações cometidas contra crianças, mulheres, negros e homossexuais tinham a mesma importância e visibilidade do que a discussão em torno dos direitos políticos. Não se pode afirmar que não havia violência contra estes outros grupos ou que não havia nenhum tipo de preocupação com seus direitos. Na verdade, a organização de tais grupos na luta por seus direitos ainda era incipiente naquela época.

Nas delegacias, nas ruas, de acordo com Silva (2007), alguns indivíduos desviantes parecem conhecer, na própria pele, o que significa ser considerado como escória da sociedade, não tendo seus direitos reconhecidos. Isso porque, aparentemente, as relações sociais entre as instituições policiais brasileiras e, por exemplo, os homossexuais, gays, lésbicas e, principalmente, travestis, segundo diferentes estudos, depoimentos, relatórios e denúncias, nunca foram tranqüilas. E não se trataria de uma relação de simples estranhamento ou de mal-estar causado pelo encontro de indivíduos diferentes, pois aqui estamos falando da violência exercida por um grupo sobre o outro. Até o início dos anos noventa, do século 20, tinha-se notícia de expulsões de militares gays, quando flagrados em "atos imorais", não importando o posto ocupado na hierarquia militar. E quanto à abordagem de policiais a travestis na rua, bem, aí o cenário ganhava ares de tragédia urbana: foram relatados insultos, espancamentos, agressões, humilhações, extorsões e histórias de terror contadas ao pé do ouvido ou sem receio algum em seminários de discussões sobre violência, inclusive sobre afogamentos de travestis no rio Guaíba, em Porto Alegre.

Bobbio (1992) reconhece uma ampliação crescente na importância atribuída pelos movimentos, partidos e governos na afirmação, reconhecimento e proteção dos direitos humanos. Se por um lado é possível fazermos uma leitura da contemporaneidade como violenta em quase todas as suas dimensões, por outro lado temos uma potencialização de grupos responsáveis pela defesa dos direitos das ditas minorias. Bobbio, de forma muito apropriada e otimista, sublinha: "quando o inteiro decurso histórico da humanidade parece ameaçado de morte, há zonas de luz que até o mais convicto dos pessimistas não pode ignorar".

Conforme Griza (1999), diversos estudos sobre a polícia brasileira enfocam o "projeto de disciplinamento" da sociedade pelo Estado, encontrado nos discursos e práticas das elites políticas da virada do século 19. A polícia era um instrumento importante naquele projeto. Convocada 
a participar do "empreendimento disciplinar", a intervenção policial iria além da repressão às classes trabalhadoras. Aliada ao discurso médico, ela contribuía na vigilância e controle de categorias sociais "potencialmente criminosas": os sem trabalho, mendigos, vadios, menores, prostitutas, ocupantes de um espaço público que necessitava ser higienizado e regrado. Sem deixar de apontar o papel repressivo da polícia, tais estudos enfatizavam a sua "função disciplinadora".

Ainda no que diz respeito ao disciplinamento da sociedade brasileira pelos aparelhos repressores de Estado, é preciso lembrar que o modelo brasileiro de ordem e progresso, estampado inclusive em nossa bandeira, carrega a imagem da índole de um povo supostamente pacífico e ordeiro. Nesse sentido, o ideal positivista no Brasil muito triunfou e forjou a necessidade de construção de uma identidade nacional ordeira, com forte vocação ao distanciamento e silenciamento diante dos conflitos sociais; uma vocação intimamente associada ao caráter oficial e desumano de que as instituições policiais dispuseram para fazê-la vingar (Taschetto, 2002).

Apesar dos avanços no campo social após a ditadura militar, uma clara sensação de paralisia ainda permeia as práticas policiais, podendo ser evidenciada através dos últimos relatórios produzidos pela Anistia Internacional sobre a tortura policial no Brasil. Estes relatórios apontam a continuidade acentuada da tortura e a permanência da impunidade de seus executores, colocando em questionamento os atuais modelos de que dispomos no que concerne à formação do agente de segurança publica e os princípios que a norteiam.

São pressupostos que, numa leitura aligeirada, não corresponderiam àquelas formas de poder localizadas por Foucault na formação histórica das sociedades capitalistas, nas pesquisas sobre o nascimento da instituição carcerária e a constituição do dispositivo da sexualidade. Formas sedutoras e táticas que têm uma eficácia produtiva, uma riqueza estratégica, uma positividade. Um tipo de poder que teria como objetivo atingir o corpo humano, não para destruí-lo, supliciá-lo, mutilá-lo, mas para aprimorá-lo, adestrá-lo, torná-lo útil e dócil. Foucault (1988a) diz que o que faz com que o poder se mantenha é simplesmente que ele não pesa só como uma força que diz não, mas que de fato ele permeia, produz coisas, induz ao prazer, forma saber, produz discursos. Deve-se considerá-lo como uma rede produtiva que atravessa todo o corpo social muito mais do que uma instância negativa que tem por função reprimir. 


\section{Considerações finais}

Diante deste panorama aparentemente desolador, o que mais nos restaria sublinhar além das críticas aqui postas ao sistema policial brasileiro? Com certeza, empreender algum tipo de desterritorialização nos cursos de formação e atualização. Desterritorializar significa mexer no comportamento de exceção institucional das polícias. Ainda hoje elas se posicionam fortemente como instituições distanciadas das demais instituições, mantendo seu velho habitus, pois ainda "operam como se fossem instituições à parte ou como se fossem instituições de outro Estado. Ou, mais precisamente, assumem-se como exceção institucional em relação à institucionalidade como conjunto ou universo" (Bisol, 2002, p. 11). Para Bisol, esse postular-se como exceção é um fenômeno político demasiado grave para que não o questionemos e para que não se procure convertê-lo em objeto de estudo das ciências políticas e sociais.

A referência de Bisol à exceção institucional na qual ainda se posicionam as polícias é interpretada por ele a partir da própria disposição que o texto constitucional estabelece. Ele toma emprestado o termo forclusão da terminologia lacaniana, empregado no sentido de que as instituições policiais, em especial as polícias militares dos estados federados, cercamse de dispositivos auto-reguladores, com o intuito de permanecerem com o estatuto de exceção institucional, cercando-se de instituições satélites, como a Justiça Militar, o Cárcere Militar, o Ministério da Defesa, o Direito Militar, a Casa Militar, os Regimentos Disciplinares Internos e outras (Taschetto, 2002). Não fosse assim, "como efeito de estrutura, as instituições militares estariam, como as outras, interinstitucionalmente comprometidas com a justiça comum e perderiam o estatuto de exceção e com ele o poder de se situar no lado de fora da institucionalidade" (Bisol, 2002, p. 12).

Além disso, os espaços físicos e subjetivos nas corporações policiais, especialmente nas polícias militares, são altamente estratificados e hierarquizados, territorializados pelo discurso do disciplinamento social, onde impera a velha lógica do "manda quem pode, obedece quem precisa". Isso faz com que alguns policiais, identificados com uma "visão sombria do mundo social" (Monet, 2001, p. 129), assumam para si uma espécie de causa-missão de salvar a sociedade da barbárie, projetando essas estruturas institucionais duras nas classes desfavorecidas e nos grupos minoritários, em forma de violência física e autoritarismo.

Deixando gradativamente de serem caixas-pretas, cada vez mais assistimos a uma abertura das instituições policiais brasileiras, justamente 
porque se interpõe o elemento híbrido, que se reforça pelo confronto entre os controles no processo nestas instituições. É também um local de tensão entre o arcaico na tradição e as novas demandas sobre segurança pública advindas de setores da sociedade (Taschetto, 2002).

Durante o período de gestão do secretário José Paulo Bisol na Secretaria de Segurança Pública do RS ocorreram significativas inovações na grade curricular dos Cursos de ações básicas de segurança pública: uso da força e arma de fogo e Curso de formação integrada, inovações que, apesar de se fundamentarem nos Direitos Humanos, não foram bem acolhidas pela ampla maioria dos policiais, uma vez que se propunham a ressignificar as práticas policiais à luz desses direitos e dos tratados internacionais sobre o uso da força e da arma de fogo. Segundo Monet (2001, p. 309), "a inovação se choca com a hostilidade da base, e até de certos hierarcas, então, por conviçção, por demagogia - ou por ambas as coisas ao mesmo tempo -, a experiência acaba quando o reformador deixa o posto". E foi exatamente o que aconteceu naquela gestão de que participamos como educadores: mudou a gestão, mudou o entendimento de como devem ser as atuações das polícias, e tudo parece retornar à estaca zero.

Não existem fórmulas a serem aplicadas nem tampouco modelos a ser seguidos. Por outro lado, nos últimos anos, em algumas regiões do Brasil, algumas experiências de mudanças na formação e atualização de policiais poderiam ser potencializadas e aprimoradas, mudando a imagem da polícia de dentro para fora e não - como querem muitos - de fora para dentro. Se os policiais se queixam constantemente da falta de reconhecimento do seu trabalho é porque uma parte significativa da população está descontente com o trabalho por eles exercido. Outro aspecto a ser considerado é que mudanças neste setor levam tempo para serem sentidas, por isso mesmo a importância de haver continuidade nas políticas de segurança pública.

\section{Referências}

ADORNO, Sérgio; CARDIA, Nancy. Dilemas do controle democrático da violência: execuções sumárias e grupos de extermínio. In: SANTOS (Org.). Violência em tempo de globalização. São Paulo: Hucitec, 1999.

ADORNO, Sérgio et al. Estratégias de intervenção policial no Estado Contemporâneo. Revista Tempo Social, USP, v. 9, 1997.

BISOL, José Paulo. Forclusão institucional. In: FREITAS, Isabel; MARIANO, Benedito Domingues (Org.). Policia: desafio da democracia brasileira. Porto Alegre: Corag, 2002.

BOBBIO, Norberto. A era dos direitos. Rio de Janeiro: Campus, 1992. 
FOUCAULT, Michel. A ordem do discurso. São Paulo: Loyola, 1996. . Microfísica do poder. Rio de Janeiro: Graal, 1988a. . Vigiar e punir: nascimento da prisão. Petrópolis: Vozes, 1988b. . El sujeto y el poder. Revista Mexicana de Sociología. UNAM, México, v. 2, n. 3, jul.-set. 1988c. . Dits et écrits IV: 1980-1988. Paris: Gallimard, 1994.

GRIZA, Aida. Policia técnica e ciência: o processo de incorporação dos saberes técnico-científicos na legitimação do ofício de policial. 1999. Dissertação (Mestrado em Sociologia) - Universidade Federal do Rio Grande do Sul, Porto Alegre, 1999.

GULLO, Álvaro de A. e S. Violência urbana um problema social. Tempo Social, Revista de Sociologia da USP, São Paulo, v. 10, n. 1, p. 105-119, 1989.

MONET, Jean-Claude. Polícias e sociedades na Europa. São Paulo: Edusp, 2001.

RELATÓRIO AZUL, 1996 - Comissão de Cidadania e Direitos Humanos. Assembléia Legislativa/RS.

SILVA, Rosimeri Aquino da. Identidades heterogêneas na contemporaneidade violenta: um estudo a partir de uma sala de aula singular. 2007. Tese (Doutorado em Educação) - Programa de Pós-Graduação em Educação, Universidade Federal do Rio Grande do Sul, Porto Alegre, 2007.

SKIDMORE, Thomas. Brasil de Castelo a Tancredo. Rio de Janeiro: Paz e Terra, 1988.

TASCHETTO, Leonidas R. Profissão policial: efeitos de sentidos de ambivalência nos dizeres dos alunos-policiais (o que dizem, como dizem e por que dizem?). 2002. Dissertação (Mestrado em Educação) - Programa de Pós-Graduação em Educação, Universidade Federal do Rio Grande do Sul, Porto Alegre, 2002.

Recebido em: 7 jul. 2008 Aprovado em: 11 set. 2008 